\title{
Dual-State Emission in Molecular Rotors with Reorientable
}

\section{Benzotriazole Acceptors}

Lizbeth A. Rodríguez-Cortés, ${ }^{1}$ Federico J. Hernández, ${ }^{2}$ Mario Rodríguez, ${ }^{3}$ Ruben A. Toscano, ${ }^{1}$ Arturo Jiménez-Sánchez, ${ }^{1}$ Rachel Crespo-Otero, ${ }^{* 2}$ and Braulio Rodríguez-Molina*1

${ }^{1}$ Instituto de Química, UNAM, Circuito Exterior s/n, Ciudad Universitaria, Coyoacán, Mexico City, Mexico.

${ }^{2}$ Department of Chemistry, Queen Mary University of London, London, UK.

${ }^{3}$ Research Group of Optical Properties of Materials (GPOM), Centro de Investigaciones en Óptica, ClO, Apdo., Postal 1-948, 37000 León Gto, México.

\section{Abstract}

Dual-State Emission (DSE) of organic molecules in both solution and solid-state is an elusive property that has recently drawn significant interest. In this work, we report two molecular rotors 1 and 2 with exceptional photoluminescence $(\mathrm{PL})$ in solution $\left(\Phi_{\mathrm{PL}}=0.53\right.$ and $\Phi_{\mathrm{PL}}=$ $0.43)$ and in the solid state $\left(\Phi_{P L}=0.92\right.$ and $\left.\Phi_{P L}=0.84\right)$. To the best of our knowledge, this is the first report containing Donor- $\pi$-Acceptor- $\pi$-Donor (D- $\pi-A-\pi-D)$ compounds with high quantum yields in both states that features a rotary acceptor. Furthermore, we describe the marked variations in PL in solution upon polarity and viscosity changes. TD-DFT computations indicate that these changes are facilitated by the fast molecular rotation in these molecules. The symmetry (or lack of it) in $\mathbf{1}$ and $\mathbf{2}$ plays a crucial role in producing 
noticeable differences in the X-ray crystal arrays with variations in the solid-state PL. We attribute this DSE behavior to the favorable combination of the D- $\pi-A-\pi-D$ architecture and the twisted conformations adopted in the solid state.

\section{Introduction}

Organic fluorescent materials have been investigated for numerous applications, either as biological probes (solution) ${ }^{1}$ or as emissive layers in optoelectronic devices (solid state). ${ }^{2}$ The media can significantly tune their emissive properties, with many molecules displaying a contrasting behavior in dilute solution and the solid-state. Most traditional fluorophores exhibit strong photoluminescence (PL) in solution; however, they often experience quenching upon aggregation or crystallization (Aggregation-Caused Quenching, ACQ) ${ }^{3}$ due to several non-radiative pathways such as vibrational relaxation and intermolecular rotations. Conversely, a conjugated compound with weak emission in solution might show strong emission after forming aggregates (Aggregation-Induced Emission, AIE) ${ }^{4}$ due to the restriction of the molecular mobility in the solid-state. ${ }^{5}$ Similarly, molecules with weak emission in solution and amorphous phase but bright fluorescence in the crystalline form are described by the crystallization-induced emission phenomenon (CIE). ${ }^{6}$ These seemingly exclusive effects suggested that molecules featuring strong emission in both states are atypical and their design is challenging. 
Recent reports have demonstrated that the design of molecules with bright emission in both states termed Dual-State Emitters $(D S E)^{7}$ is achievable. Some strategies include the suppression of $\pi-\pi$ stacking interactions upon crystallization through the inclusion of voluminous peripheral groups. ${ }^{8}$ For example, Zhao et al. reported that alkyl side chains allow the 'self-isolation' of a fluorophore. ${ }^{9}$ Similarly, Patil et al. included highly twisted molecular fragments and bulky units as a strategy to minimize of $\pi-\pi$ interactions.${ }^{10}$ In this work, we explored the use of $D-\pi-A-\pi-D$ systems as DSE. The use of Donor-Acceptor architectures in organic fluorophores results in longer emission wavelengths due to the reduced HOMO-LUMO gap. ${ }^{11}$ This can be further altered by changing the nature of the donor and acceptor moieties, ${ }^{12}$ the length of the $\pi$-bridge, ${ }^{13}$ or the electronic architecture patterns. ${ }^{14}$ In these molecules, the stabilization of excited state intramolecular chargetransfer (ITC) could enable stimuli-responsive systems, opening the way to new applications with local control of emission by the microenvironment. ${ }^{15}$ This design might enable applications in organic light-emitting diodes (OLEDs), ${ }^{16}$ organic transistors (OFETs), ${ }^{17}$ photovoltaic cells (OPVCs), ${ }^{18}$ organic solar cells (OSCs), ${ }^{19}$ and molecular imaging, ${ }^{20}$ among others. 
Donor- $\pi$-Acceptor- $\pi$-Donor
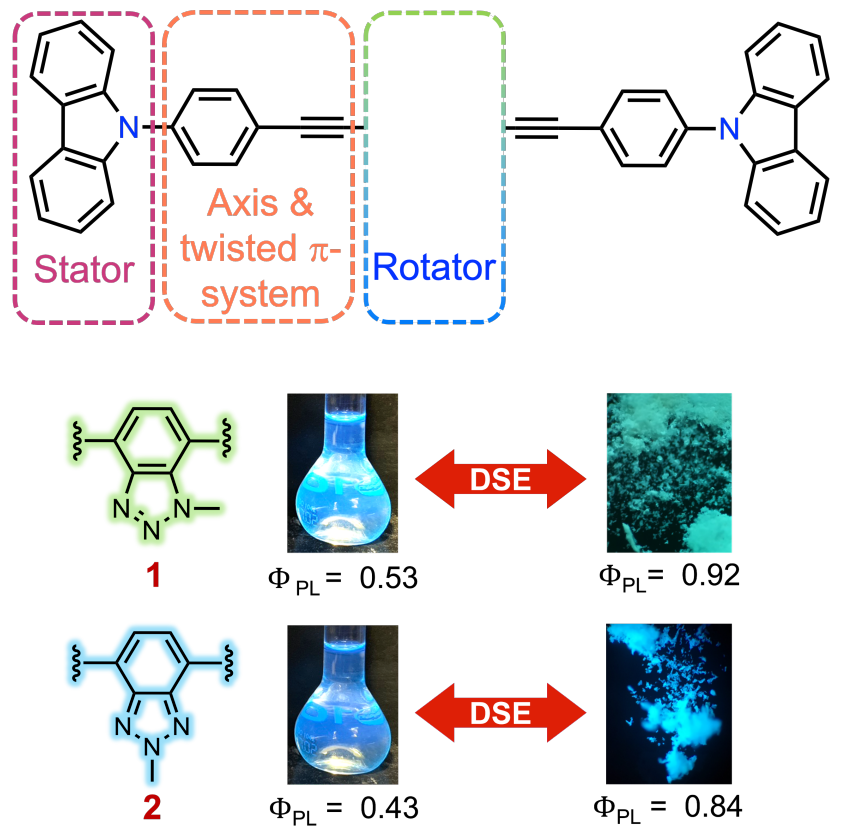

Figure 1. Design strategy of the $D-\pi-A-\pi-D$ molecular rotors reported here.

During our investigations in conjugated molecular rotors, we reported that surrounding a diethynylphenylene rotator with carbazole stators creates a compound with blue fluorescence. ${ }^{21}$ We hypothesized that including a formal acceptor into this molecular design could render a new series of $D-\pi-A-\pi-D$ compounds with red-shifted fluorescence. The envisioned design integrates the elements of a molecular rotor: a carbazole portion acting as the component with the larger moment of inertia (stator) while driving the crystallization of the molecules, and a reorientable component (rotator), which would be able to respond to an external stimulus (see Figure 1). 
This work describes the synthesis and characterization of two molecular rotors $\mathbf{1}$ and $\mathbf{2}$ that are good Dual-State Emitters. The combination of reorientable 1-methyl-[1,2,3]benzotriazole and 2-methyl-[1,2,3]-benzotriazole rotators linked through the alkyne axis to the peripheral carbazole is a key feature of this design. We focused on these weak acceptors because they have not been reported in molecular rotors. Other benzotriazole derivatives have been successfully used as acceptors in other $D-\pi-A-\pi-D$ dyes. ${ }^{22}$ Notably, the synthesized rotors presented not only an acceptable PL in solution ( $\Phi_{\mathrm{PL}}=0.53$ for 1 and $\Phi_{P L}=0.43$ for 2$)$ but most importantly, a remarkable PL in the solid-state for $\left(\Phi_{P L}=0.92\right.$ for 1 and $\Phi_{P L}=0.84$ for 2). Our investigation of the effects of solvent polarity, viscosity, aggregation, and excited state calculations helped us understand how the benzotriazole reorientation can respond to different stimuli, showing changes in the wavelength and intensity of the emission in solution. Moreover, through a combination of single-crystal and powder X-ray studies, solid-state NMR ${ }^{13} \mathrm{C}$ CPMAS experiments, and solid-state PL measurements, we describe how the twisted conformation of $\mathbf{1}$ and $\mathbf{2}$ dictate each crystal array, and ultimately, the emission of the corresponding solids. This detailed description may incentivize the search for new DSE in the future by including similar elements.

\section{Results and Discussion}

\section{Synthesis and characterization}

Compounds 1 and 2 were obtained in moderate yields of $55 \%$ and $52 \%$, by means of Pdcatalyzed Sonogashira cross-coupling reactions between 4,7-dibromo-1-methyl-[1,2,3]- 
benzotriazole (7a) or 4,7-dibromo-2-methyl-[1,2,3]benzotriazole (7b), and the carbazolebased electron donating $N$-(4-ethynylphenyl) carbazole 8 (Scheme 1 and Scheme 2).

Scheme 1. Synthetic route for the acceptor moieties $\mathbf{7 a}$ and $\mathbf{7 b}$.
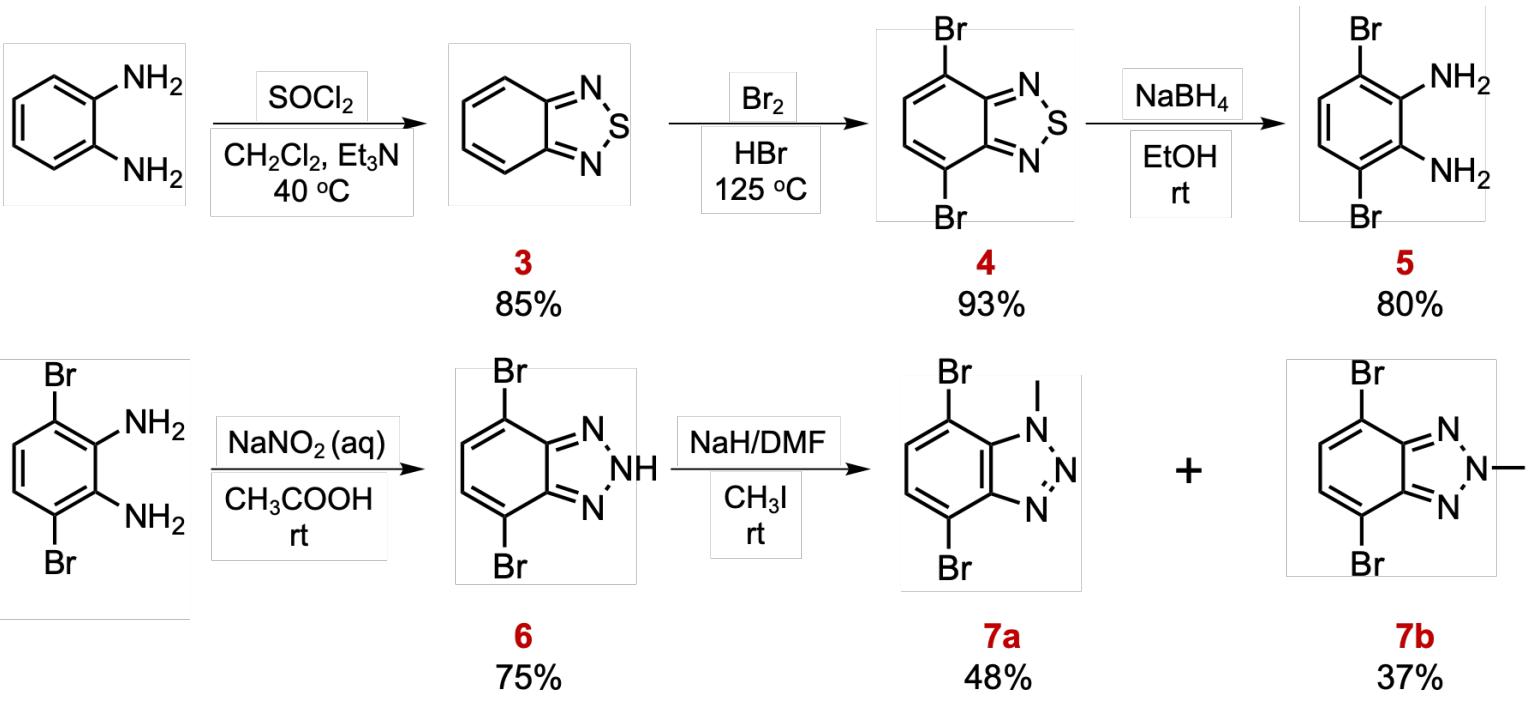

Scheme 2. Synthesis of the $D-\pi-A-\pi-D$ compounds, $\mathbf{1}$ and $\mathbf{2}$.

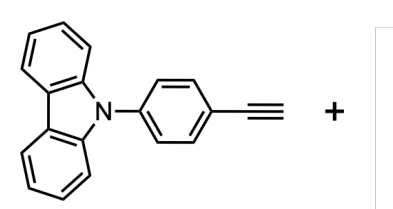

8<smiles>[C+]#Cc1ccc(-n2c3ccccc3c3ccccc32)cc1</smiles>

8<smiles>Cn1nnc2c(Br)ccc(Br)c21</smiles>

$7 a$ $48 \%$<smiles>Brc1ccc(Br)c2nc(NC3CCCC3)nnc12</smiles>
$7 \mathrm{~b}$ $37 \%$<smiles></smiles><smiles>CNNc1c(C#Cc2ccc(-n3c4ccccc4c4ccccc43)cc2)ccc(C#Cc2ccc(-n3c4ccccc4c4ccccc43)cc2)c1NN</smiles>
1 $55 \%$

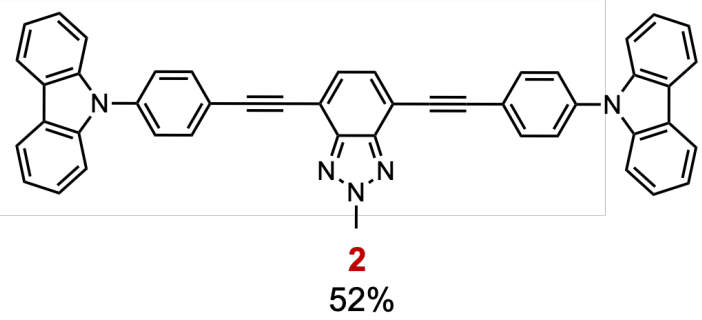


Compound $\mathbf{1}$ is asymmetric due to the position of the methyl group in the nitrogen atom N1. This asymmetry was evident in the ${ }^{1} \mathrm{H}-\mathrm{NMR}$ and ${ }^{13} \mathrm{C}-\mathrm{NMR}$ spectra; however, with the help of the methyl signal at $36.2 \mathrm{ppm}$, the signals were completely assigned using 2D NMR experiments $\left({ }^{1} \mathrm{H}-{ }^{1} \mathrm{H}\right.$ COSY, ${ }^{1} \mathrm{H}-{ }^{13} \mathrm{C}$ HSQC, and ${ }^{1} \mathrm{H}_{-}{ }^{13} \mathrm{C}$ HMBC see Supporting Information). For example, the four signals at $96.7,95.7,85.8$, and $85.3 \mathrm{ppm}$ were assigned to the alkyne carbon atoms (C21, C11, C12, and C20, respectively). Conversely, the corresponding NMR spectra of symmetric rotor $\mathbf{2}$ show considerably fewer signals. For example, only two peaks at 95.9 and $86.1 \mathrm{ppm}$ corresponding to the alkyne groups (C12 and C16, respectively) in the

${ }^{13} \mathrm{C}-\mathrm{NMR}$ spectrum were observed, and thus a complete assignment was also carried out (see Figure S2).

\section{Photophysical properties of compounds 1 and 2}

\section{Polarity experiments}

The photophysical properties of the target compounds were examined first in THF solution. The UV-Vis absorption spectra (Figure 2, dotted line) consist of two bands, the first in the range of $270-320 \mathrm{~nm}$, and the second in the range $330-420 \mathrm{~nm}$, which were assigned to an intramolecular charge transfer (ICT) and a $\pi \rightarrow \pi *$ electronic transition, respectively (Figure $4 a$ and Figure S18). The $\pi \pi^{*}$ state involves a bond alternation between $S_{1}$ and $S_{0}$ states and has some ICT character. The maximum wavelengths of emission in diluted THF $(40 \mathrm{mM})$ are $451 \mathrm{~nm}$ for compound 1 and $453 \mathrm{~nm}$ for compound 2, respectively. Both compounds exhibited large Stokes shifts of ca. $4500 \mathrm{~cm}^{-1}$, associated with ICT. Rotors 1 and $\mathbf{2}$ displayed 
acceptable fluorescence quantum yields $\Phi_{\mathrm{PL}}=0.53$ and $\Phi_{\mathrm{PL}}=0.43$, respectively. These results indicate that the position of the methyl groups has minimal impact on the fluorescence of these molecules in solution.

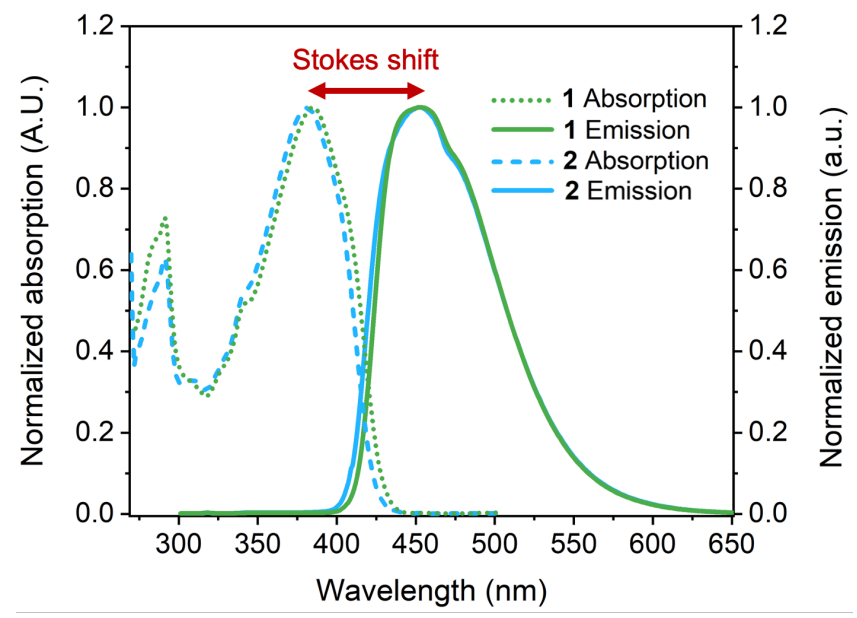

Figure 2. Normalized absorption (dotted lines) and fluorescence emission (solid lines) spectra of the investigated molecules recorded in THF (40 $\mu \mathrm{M})$.

After establishing the emission of the title compounds in THF, we evaluated the effect of the solvent polarity. The UV-Vis spectra of $\mathbf{1}$ and $\mathbf{2}$ displayed small changes, indicating that the polarity does not significantly affect the corresponding ground states. Conversely, in both rotors, the fluorescence spectra showed a positive solvatochromic behavior, i.e., a noticeable bathochromic shift was observed when the polarity was increased ( 


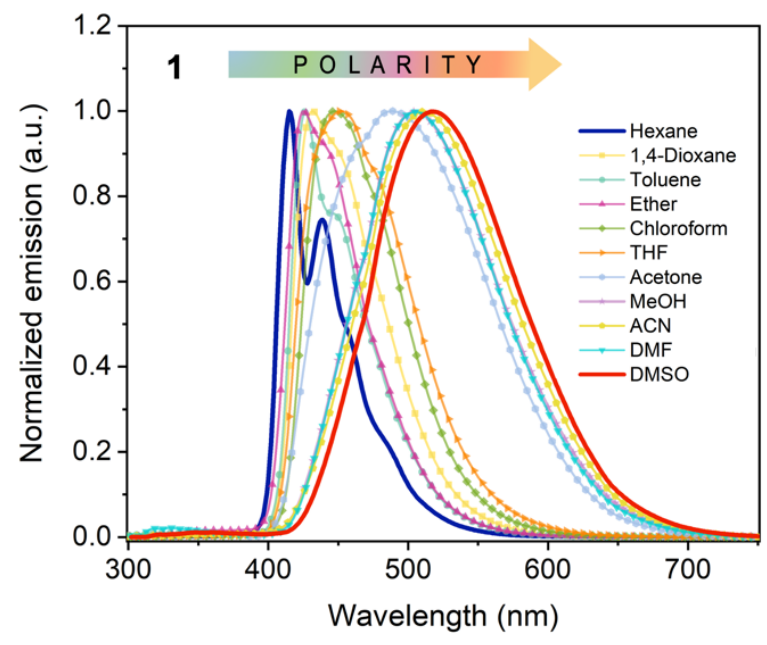

Figure 3. Normalized emission spectra of compound 1 recorded in various solvents ( $40 \mathrm{mM}$ ).

, Figure S10 and Table 1).

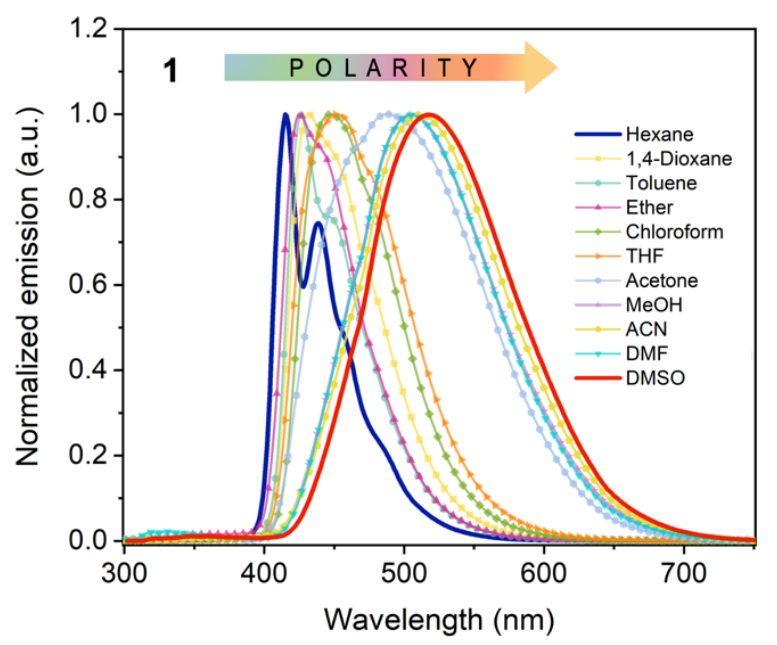

Figure 3. Normalized emission spectra of compound 1 recorded in various solvents ( $40 \mathrm{mM})$.

Excited states of rotors 1 and $\mathbf{2}$ possess a marked solvatochromic effect, indicating that the central benzotriazoles can rotate after interacting with the solvents, agreeing with the expected behavior for $D-\pi-A-\pi-D$ molecules. 
The structured peak of the emission in hexane became broad and structureless in DMSO, showing a significant red shift of 102 and $97 \mathrm{~nm}$ for 1 and 2, respectively. The computed absorption and emission transitions, computed with TD-CAM-B3LYP/6-31G(d) in solution, are in excellent agreement with the experimental values (see Table 1). The maximum deviation for absorption and emission are 0.10 and $0.24 \mathrm{eV}$, agreeing with the positive solvatochromic effect with the dielectric constant increase.

Table 1. Photophysical properties of $\mathbf{1}$ and $\mathbf{2}$ in various organic solvents

\begin{tabular}{|c|c|c|c|c|c|c|c|}
\hline \multicolumn{3}{|c|}{ Compounds } & \multicolumn{2}{|c|}{1} & \multicolumn{3}{|c|}{2} \\
\hline Solvent & $\begin{array}{c}\text { Dielectric } \\
\text { constant (e) }\end{array}$ & $\begin{array}{c}\lambda_{\text {abs }}{ }^{[a]} \\
(\mathrm{nm})\end{array}$ & $\begin{array}{l}\lambda_{\mathrm{em}}{ }^{[\mathrm{b}]} \\
(\mathrm{nm})\end{array}$ & $\begin{array}{c}\text { Stokes } \\
\text { Shift } \\
\left(\mathrm{cm}^{-1}\right)\end{array}$ & $\begin{array}{c}\lambda_{\text {abs }}{ }^{\text {[a] }} \\
(\mathrm{nm})\end{array}$ & $\begin{array}{l}\lambda_{\text {em }}{ }^{[b]} \\
(\mathrm{nm})\end{array}$ & $\begin{array}{c}\text { Stokes } \\
\text { Shift } \\
\left(\mathrm{cm}^{-1}\right)\end{array}$ \\
\hline Hexane & 0.00 & $\begin{array}{c}382 \\
370^{[c]}\end{array}$ & $\begin{array}{c}415 \\
441^{[c]}\end{array}$ & $\begin{array}{c}2082 \\
4317^{[c]}\end{array}$ & $\begin{array}{c}385 \\
380^{[c]}\end{array}$ & $\begin{array}{c}421 \\
458^{[c]}\end{array}$ & $\begin{array}{c}2221 \\
4480^{[c]}\end{array}$ \\
\hline 1,4-Dioxane & 2.22 & 382 & 431 & 2976 & 385 & 435 & 2986 \\
\hline Toluene & 2.38 & 385 & 426 & 2450 & 389 & 433 & 2612 \\
\hline Ether & 4.27 & 377 & 425 & 2996 & 381 & 428 & 2882 \\
\hline $\mathrm{CHCl}_{3}$ & 4.81 & 382 & 448 & 3857 & 386 & 451 & 3734 \\
\hline THF & 7.52 & $\begin{array}{c}381 \\
378^{[c]}\end{array}$ & $\begin{array}{c}451 \\
463^{[c]}\end{array}$ & $\begin{array}{c}4074 \\
4849 \text { [c] }\end{array}$ & $\begin{array}{c}385 \\
385^{[c]}\end{array}$ & $\begin{array}{c}453 \\
481^{[c]}\end{array}$ & $\begin{array}{c}3899 \\
5199^{[c]}\end{array}$ \\
\hline Acetone & 21.01 & 378 & 489 & 6005 & 381 & 487 & 5755 \\
\hline Methanol & 33.00 & $\begin{array}{c}380 \\
381^{[c]}\end{array}$ & $\begin{array}{c}506 \\
471^{[c]}\end{array}$ & $\begin{array}{c}6553 \\
5015^{[c]}\end{array}$ & $\begin{array}{c}383 \\
391^{[c]}\end{array}$ & $\begin{array}{c}508 \\
490^{[c]}\end{array}$ & $\begin{array}{c}6425 \\
5167^{[c]}\end{array}$ \\
\hline $\mathrm{ACN}$ & 36.64 & 382 & 511 & 6609 & 380 & 514 & 6654 \\
\hline DMF & 36.70 & 382 & 505 & 6415 & 380 & 515 & 6898 \\
\hline DMSO & 46.68 & $\begin{array}{c}384 \\
381^{[c]} \\
\end{array}$ & $\begin{array}{c}517 \\
472^{[c]} \\
\end{array}$ & $\begin{array}{c}6699 \\
5059^{[c]} \\
\end{array}$ & $\begin{array}{c}380 \\
391^{[c]}\end{array}$ & $\begin{array}{c}518 \\
491^{[c]} \\
\end{array}$ & $\begin{array}{c}7011 \\
5194^{[c]} \\
\end{array}$ \\
\hline
\end{tabular}

[a] Absorption wavelength; [b] Emission wavelength; [c] Bold red values were calculated with TD-CAM-B3LYP/6-31G(d). 
The increase of the Stokes shift is frequently associated with the push-pull effects in D- $\pi$-A$\pi$-D molecules because the ground states $\left(S_{0}\right)$ are less polar than the corresponding excited states $\left(S_{n>0}\right)$. Therefore, increasing the polarity of the solvent stabilizes the conformation of the molecule and decreases the energy of the excited state, resulting in emission at higher wavelengths. ${ }^{23}$ These results indicate that despite the relatively low acceptor strength of the benzotriazole component, its reorientation is possible and is driven by the polarity of the media.

The observed effect of the solvent polarity can be evaluated using the Lippert-Mataga equation. ${ }^{24}$ Figure S12 in the Supporting Information contains the fitting lines for $\mathbf{1}$ and $\mathbf{2}$ with a slope of 13017.4 and 13991.9 , respectively. A positive slope in the Lippert-Mataga plot corroborates that the difference of the dipole moments between the excited and ground-state increases with the solvent polarity. ${ }^{25}$ The solvatochromic properties of the two compounds were confirmed by the dependency of their Stokes shift on the empirical parameters of the solvent polarity, Figure S12 (a-b). The relatively linear fitting for 1 and 2 indicates solute solvent interactions agreeing with the solvatochromic effect. ${ }^{26}$ 
a)
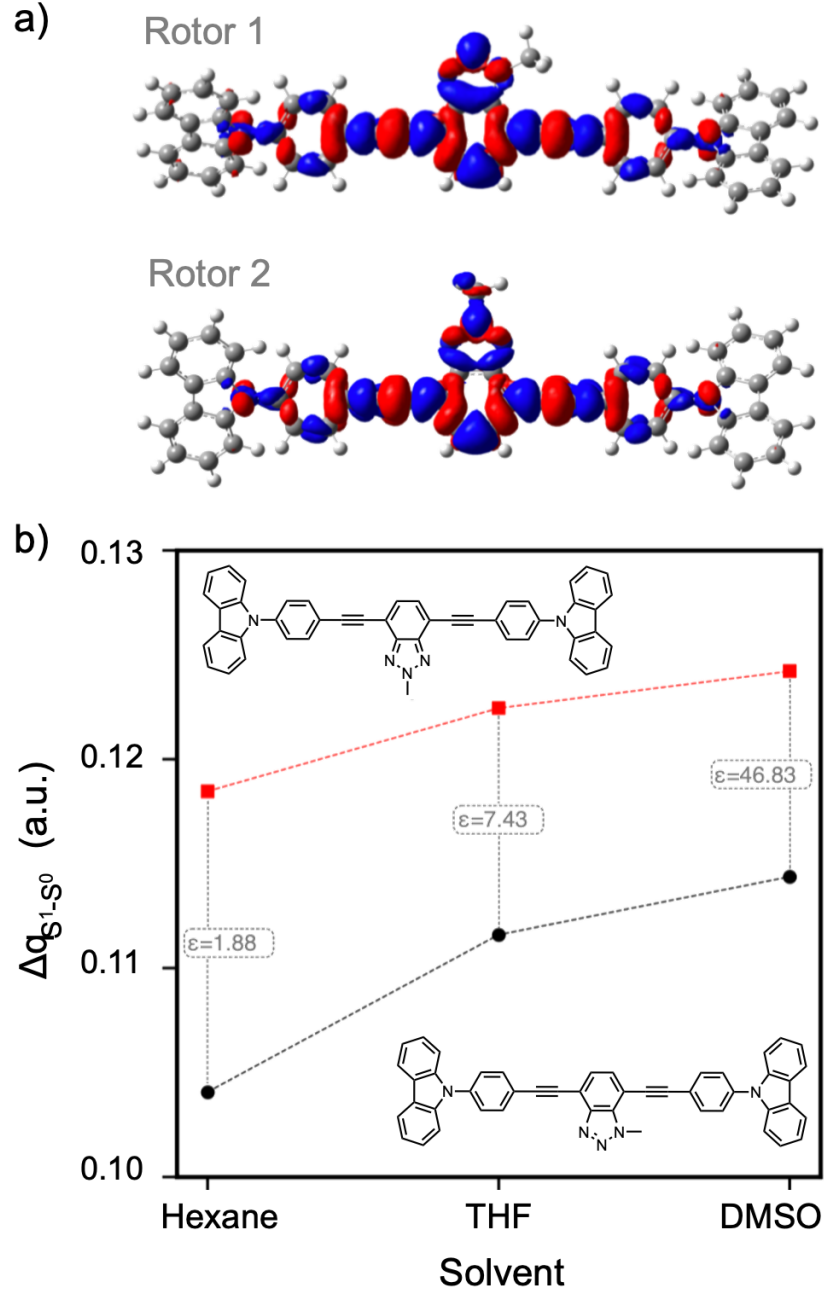

Figure 4. Electron density difference of $S_{0} \rightarrow S_{1}$ transition for both rotors (a). $S_{1}-S_{0}$ natural charge difference for the donor fragment (b) of $\mathbf{1}$ (black) and $\mathbf{2}$ (red), computed in n-Hexane, tetrahydrofuran (THF) and dimethyl sulfoxide (DMSO). The dielectric constants of the solvents are shown.

According to the natural population analysis in the $S_{1}$ state, the acceptor moiety is negatively charged at the expense of a charge donation from the carbazole donor $(\mathrm{Cz})$ and the p-system subunits (Figure $4 b$ ). The studies also corroborate that the ICT character of $\mathrm{S}_{1}$ increases with the polarity of the solvent, resulting in a bathochromic shift due to the larger 
stabilization of the excited state with respect to the ground state. ${ }^{27}$ For example, for compound 1 the differential charge between $S_{1}$ and $S_{0}$ goes from 0.105 electrons in hexane, to 0.121 electrons in DMSO.

Viscosity experiments

The first distinction between the two compounds was observed when the media viscosity changed using mixtures of methanol/glycerol. The emission profile of $\mathbf{1}$ displayed a continuous decrement of the peak at $506 \mathrm{~nm}(2.45 \mathrm{eV})$ across all glycerol contents. At the same time, the band at $315 \mathrm{~nm}$ showed a substantial rise when the viscosity was increased (Figure 5a). It is important to mention that such $\lambda$-ratiometric involving a color change in fluorescence is very uncommon. Similarly, compound $\mathbf{2}$ showed an abatement of the peak at $508 \mathrm{~nm}(2.44 \mathrm{eV})$ and a steady increase of the peak at ca. $315 \mathrm{~nm}$ in glycerol fractions between $10 \%$ and $60 \%$. However, in the latter compound, the dominant peak undergoes a hypsochromic shift at $480 \mathrm{~nm}$ along with a substantial intensity when the glycerol fraction reaches $70 \%$ (Figure $5 \mathrm{~b}$ ). At these conditions, the intensity of the peak at $315 \mathrm{~nm}$ is also noticeable, implying the coexistence of a twisted conformation at higher contents of glycerol fractions. This behavior could originate from the lower solubility of $\mathbf{2}$, which may cause a restriction of the internal rotation in highly dense environments enabling an emissive conformation. 

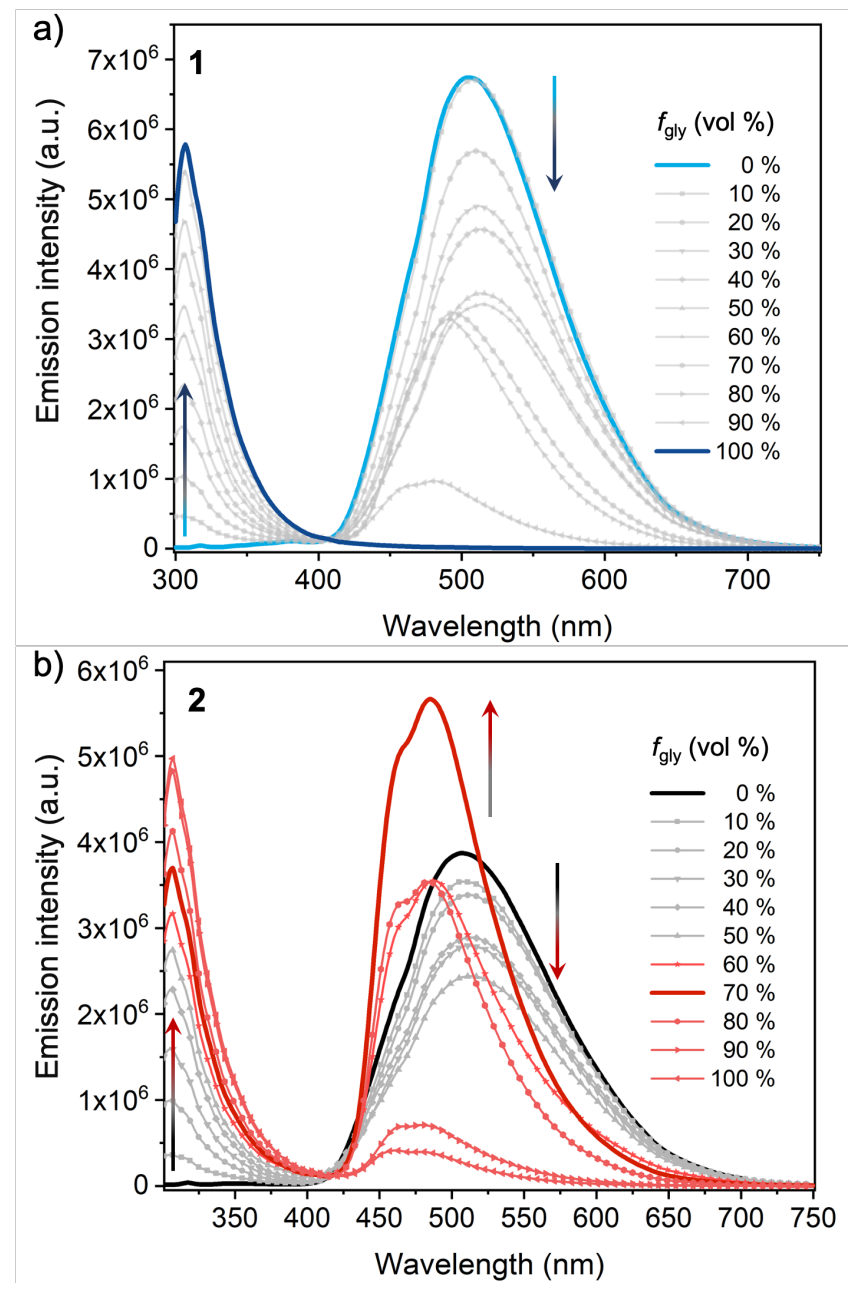

Figure 5. Normalized emission spectra of compounds (a) 1 and (b) 2 in the indicated fractions of methanol/glycerol $(40 \mu \mathrm{M})$.

The computed lowest energy emission band for $\mathbf{1}$ and $\mathbf{2}$ appears at $463 \mathrm{~nm}(2.68 \mathrm{eV})$ and $481 \mathrm{~nm}(2.58 \mathrm{eV})$, respectively, in very good agreement with the experiments. A relaxed scan of the dihedral angle between the donor and the acceptor and one of the $\pi$-systems shows a barrier to rotation of the alkyne axis of approximately $1 \mathrm{kcal} / \mathrm{mol}$ in THF (Figure S20). Therefore, the free rotation is allowed at room temperature $\left(k T^{298 K} \approx 0.6 \mathrm{kcal} / \mathrm{mol}\right)$, as reported in similar fragments in the literature. ${ }^{28}$ These results corroborate that a 
significant increase of the viscosity impacts the mobility of the molecule and could restrict the internal rotation, therefore a twisted configuration would become a local minimum. The $S_{1}-S_{0}$ energy gap ( $\left.\Delta E_{S 1-s 0}\right)$ shows a maximum blue shift in the twisted structure with a dihedral $\alpha=90^{\circ}$ (Figure S20c). The electron density difference maps of this conformation show the density is localized on the acceptor and only one of the donors, which influences the energy gaps. At this point, the values of $\Delta E_{S 1-s o}$ are $3.55 \mathrm{eV}$ (349 nm) and $3.45 \mathrm{eV}$ (359 $\mathrm{nm}$ ) for 1 and 2 respectively, which agree with the new emission band around $315 \mathrm{~nm}$, suggesting that the explored conditions provoke a twisted conformation, interrupting the electronic conjugation of the fluorophore. 


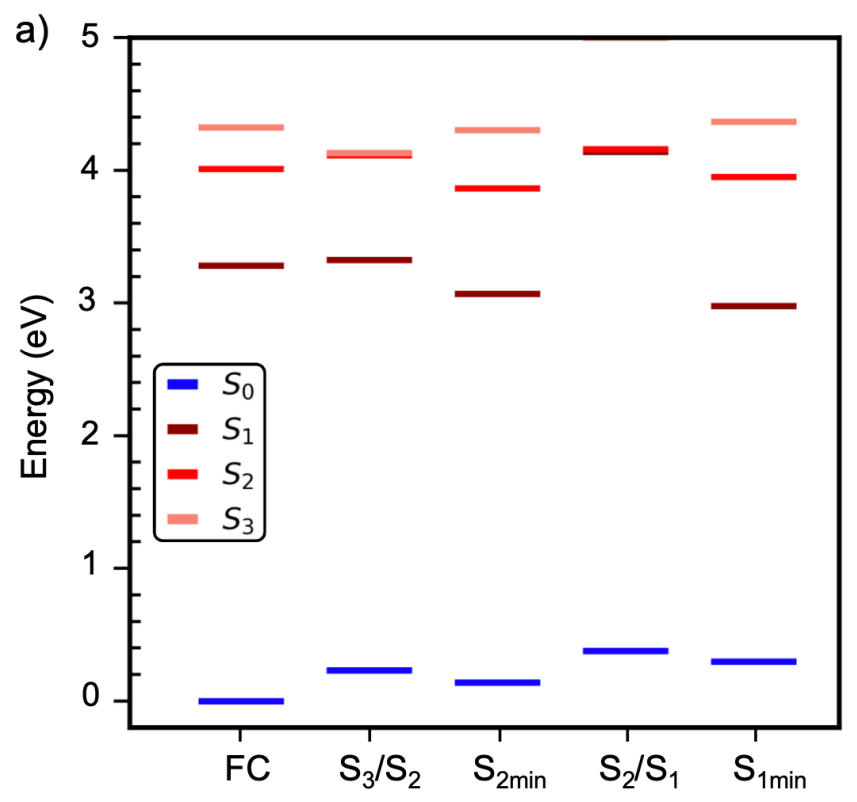

b)
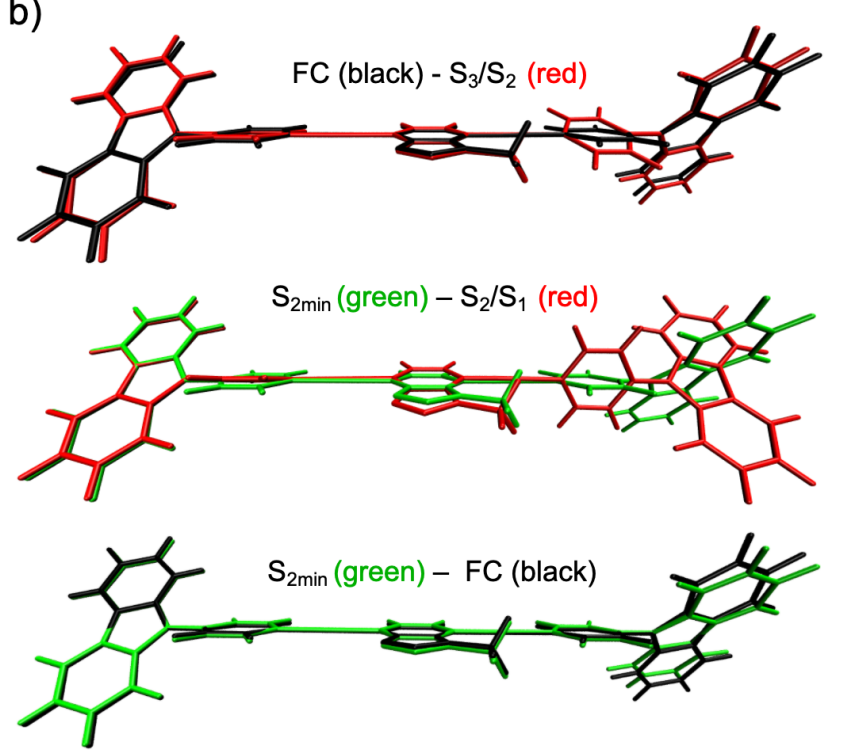

Figure 6. (a) Energy profile calculated at TD-CAM-B3LYP/6-31G(d) energies of $\mathrm{S}_{0}-\mathrm{S}_{3}$ states of 1 in THF. (b) Corresponding molecular structures at the critical points of the potential energy surface.

The observed changes can also be explained by considering the possibility of non-Kasha emission ${ }^{29}$ from $S_{2}$. Figure 6a shows the energy of different key molecular conformations in 
the potential energy surface for $\mathbf{1}$ in THF, including the minima and crossing points (data for 2 in Figure S19). Our computations indicate that after excitation with a laser of $290 \mathrm{~nm}$, the populated excited state is $S_{3}$. Vibrational relaxation, rotations and other nonradiative processes are expected to occur from this highly excited state within a few ps. A crossing between $S_{3}$ and $S_{2}$ may facilitate the internal conversion between these states. To do so, the geometry of the $S_{3} / S_{2}$ crossing requires a minimal out-of-plane distortion of the phenyl rings (Figure $6 b$ ). Once $S_{2}$ is populated, the molecule can decay to $S_{1}$ through a $S_{2} / S_{1}$ crossing, involving dihedral rotations of the phenyl rings and the carbazole groups. It can be postulated that in viscous media, the proposed intramolecular motion is restricted, and the molecule can alternatively relax to the $S_{2}$ minimum, which shows a barrier for the $S_{2} / S_{1}$ crossing of $0.28 \mathrm{eV}$. In these conditions, non-Kasha emission could happen from $\mathrm{S}_{2}$ at 333 $\mathrm{nm}(3.72 \mathrm{eV})$ which also agrees with the experimental band centered at $315 \mathrm{~nm}(3.93 \mathrm{eV})$.

\section{Changes in the emission in solution upon the addition of water}

We also evaluated the changes in the emission of $\mathbf{1}$ and $\mathbf{2}$ by adding different water fractions $\left(f_{w}\right)$ to their THF solutions to determine if these rotors undergo aggregation. For compound 1 , as the water fraction changes from $f_{w}=0 \%$ to $60 \%$ (Figure 7 ), the emission undergoes a slight bathochromic shift, and the intensity weakens gradually. Only a small increase of intensity with a hypsochromic shift is observed when the water fraction reaches $f_{w}=70 \%$. After this change, the intensity continued decreasing, probably due to the precipitation of the compound, giving rise to particles that exhibit a red-shifted emission. A similar behavior was observed in compound $\mathbf{2}$, showing a steady decrease of the emission 
followed by a slight intensity increase when the water fraction reaches $f_{w}=80 \%$ (Figure S11).

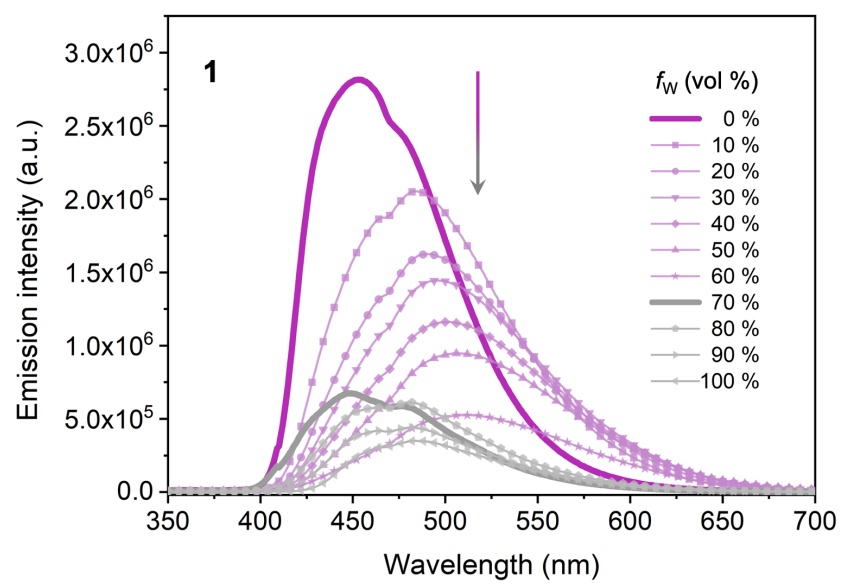

Figure 7. Emission spectra of 1 and at different water fractions, $f_{w}(40 \mu \mathrm{M})$.

To gather deeper insights of the effect of adding water into the THF solutions of $\mathbf{1}$ and $\mathbf{2}$, we analyzed two dimeric arrangements for both chromophores and their exciton splitting by TD-DFT (Figure S21). Based on the spectroscopic classification of the oscillator strengths (f), $H$-aggregates are obtained when $f_{\mathrm{s} 2}>f_{\mathrm{s} 1}$ and $J$-aggregates are favored when $f_{\mathrm{s} 1}>f_{\mathrm{s} 2}$. Considering this, the computed stable dimers can be classified as $H$-aggregates (Table 2). The predicted exciton couplings $\left(J_{\mathrm{ij}}\right)$, evaluated with the half energy splitting method, range between 3.5 and $13.6 \mathrm{meV}$. Emission from these dimers shows no appreciable red shift, which agrees well with the experimental data. A red-shift emission for $\mathbf{1}(9 \mathrm{~nm})$ and $\mathbf{2}(11$ $\mathrm{nm}$ ) is predicted only in water, indicating that the changes are likely due to the much larger polarity of water. 
Table 2. Computed oscillator strengths $(f)$, exciton couplings $\left(J_{i j}\right)$ and $S_{1}-S_{0}$ energy gaps of the dimers optimized from $\mathbf{1}$ and $\mathbf{2}$ in THF. The structures of the dimers are shown in Figure S21.

\begin{tabular}{ccccc}
\hline Compound & \multicolumn{2}{c}{ 1 } & \multicolumn{2}{c}{ 2 } \\
\hline Property & Dimer A & Dimer B & Dimer C & Dimer D \\
$\mathrm{f}_{\mathrm{S} 1}$ & 0.00 & 0.67 & 0.16 & 0.34 \\
$\mathrm{f}_{\mathrm{S} 2}$ & 5.19 & 4.66 & 4.43 & 4.53 \\
Aggregates & $\mathrm{H}$ & $\mathrm{H}$ & $\mathrm{H}$ & $\mathrm{H}$ \\
$J_{\mathrm{ij}}(\mathrm{meV})$ & 13.6 & 5.1 & 3.5 & 7.5 \\
$\Delta E_{S 1-\mathrm{SO}}(\mathrm{nm})$ & 461 & 464 & 479 & 481 \\
\hline
\end{tabular}

\section{Solid state characterization}

Single crystal X-ray diffraction studies, solid state NMR ${ }^{13} \mathrm{C}$ CPMAS and thermal analyses

After analyzing the emission of the title compounds in solution, we focused on their solidstate properties. First, we performed several crystallization experiments to obtain single crystals suitable for X-ray diffraction. Solvent-free crystals of compound $\mathbf{1}$ were grown from slow evaporation of acetone at room temperature. A detailed analysis of its molecular conformation confirmed that the two halves of the asymmetric molecule are highly twisted $\left(Z^{\prime}=1\right)$, with dihedral angles between the carbazole and its adjacent phenyl ring $=57.77^{\circ}$ 
and $56.41^{\circ}$ (Figure 8a). The relevant crystallographic data is compiled in Table S1 (Supporting Information).

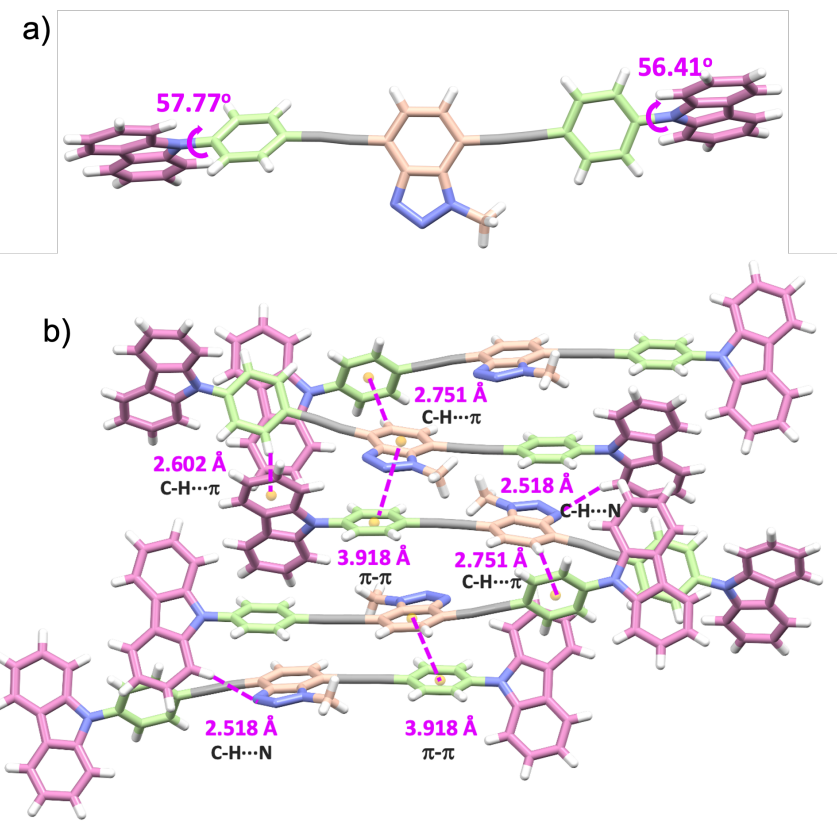

Figure 8. a) Crystal structure and b) crystalline packing of compound $\mathbf{1}$, the relevant intermolecular interactions are shown with dotted lines.

The crystalline packing of 1 is stabilized by two kinds of weak $\mathrm{C}-\mathrm{H} \cdots \pi$ interactions with the distances between $2.602 \AA$ and $2.751 \AA$, and hydrogen bonds $\mathrm{C}-\mathrm{H} \cdots \mathrm{N}(2.518 \AA)$. It is important to note that distant $\pi-\pi$ stacking interactions are also observed within the crystal, with distances of $3.918 \AA$, and therefore, they are considered weak (Figure 8b).

Single crystals of rotor $\mathbf{2}$ were obtained from slow evaporation of saturated methanol/dichloromethane solutions. Unfortunately, only very small needles were obtained at every attempt. Nevertheless, we obtained the general structure and 
connectivity of a solvent-free crystal structure using synchrotron radiation (Supporting Information, Figure S15). The structural data indicates that the conformation of rotor $\mathbf{2}$ is also highly twisted, with torsional values closer to those observed in rotor 1 . To further characterize these solid forms, we determined their solid state ${ }^{13} \mathrm{C}$ CPMAS spectra at room temperature (Supporting Information, Figure S17). The data confirmed that both rotors are solvent-free forms, with small changes the chemical shifts compared to solution NMR. In addition, both compounds were analyzed by differential scanning calorimetry (DSC) and thermogravimetric analysis (TGA) to determine their melting points and potential phase transitions. Rotor 1 melts at $285.5^{\circ} \mathrm{C}$ (Figure S13), and rotor 2 melts at $311.1{ }^{\circ} \mathrm{C}$ (Figure S14). No additional endotherms were observed, indicating that both crystalline compounds possess high thermal stability.

Phase purity and solid-state fluorescence

The molecular conformations of rotors 1 and $\mathbf{2}$ dictate their crystal arrangement and thus affect their photophysical properties in the solid state. Large batches of these solids were prepared following the crystallization conditions. The resulting powders were characterized by powder X-ray diffraction studies (PXRD) and compared against the calculated diffraction peaks, showing a high phase purity (Supporting Information, Figure S16). Subsequently, the PL properties in solids were determined. The bright green crystalline powder of 1 showed a maximum solid-state emission at $468 \mathrm{~nm}$, while the bright blue rotor 2 emits at $445 \mathrm{~nm}$. Both compounds showed a bathochromic shift of $44 \mathrm{~nm}$ (rotor 1) and $20 \mathrm{~nm}$ (rotor 2), compared with the corresponding emission band in solution (Figure 9, and Table 3). 
TD-DFT computations using X-ray crystallographic data helped us establish that the excited state of $\mathbf{1}$ is more polar than the excited state of $\mathbf{2}$. The predicted electric dipole moments for $S_{1}$ are $1.05 \mathrm{D}$ and $0.38 \mathrm{D}$ for $\mathbf{1}$ and $\mathbf{2}$, respectively. This difference in dipole moments causes the former to exhibit a red-shifted emission. The minor dipole moment of $\mathbf{2}$ is related to the higher symmetry of the molecule. These results confirm that the minor structural modifications in the acceptor moiety render significant conformational differences which influence their emissive properties.

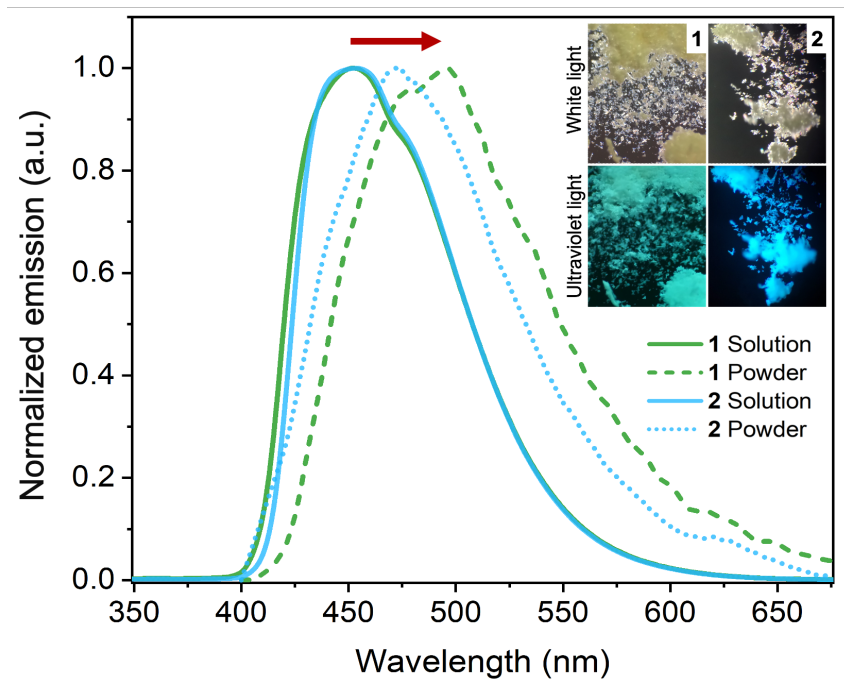

Figure 9. Comparison between solution (solid line) and solid-state emission (dotted line) for 1 and 2, respectively. Insert: Fluorescent images of the crystalline solids under UV light, $360 \mathrm{~nm}$. 
Table 3. Photophysical data of compounds 1 and $\mathbf{2}$

\begin{tabular}{ccccc}
\hline Compound & $\begin{array}{c}\lambda_{\text {em }}\left[\mathrm{nm}_{\text {[a] }}\right. \\
\text { solution }\end{array}$ & $\begin{array}{c}\lambda_{\text {em }}[\mathrm{nm}] \\
\text { solid }\end{array}$ & $\begin{array}{c}\Phi_{\mathrm{PL}}[\mathrm{b}] \\
\text { solution }\end{array}$ & $\begin{array}{c}\Phi_{\mathrm{PL}} \\
\text { solid [c] }\end{array}$ \\
\hline $\mathbf{1}$ & 451 & 497 & 0.53 & 0.92 \\
$\mathbf{2}$ & 453 & 471 & 0.43 & 0.84 \\
\hline
\end{tabular}

[a] Measured in THF (40 mM). [b] Relative quantum yields, measured using coumarin 102 in ethanol. [c] Absolute quantum yields in the solid state.

The absolute quantum yields measured with an integrating sphere revealed that both compounds are strongly emissive in the solid-state, with values of $\Phi_{\mathrm{PL}}=0.92$ and $\Phi_{\mathrm{PL}}=0.84$, for compounds 1 and 2, respectively. To the best of our knowledge, only a few compounds with intense dual-state emission have been reported, ${ }^{30}$ and the high QYs reported here are unprecedented among fluorescent rotors. Their slightly twisted conformation is crucial to avoid strong $\pi-\pi$ stacking interactions with neighboring molecules. This array suppresses the non-radiative relaxation pathways, ${ }^{31}$ thus producing the exceptional emission in the solid-state. Considering that these compounds also show significant emission in the solution, they are considered as good Dual-State Emitters. 


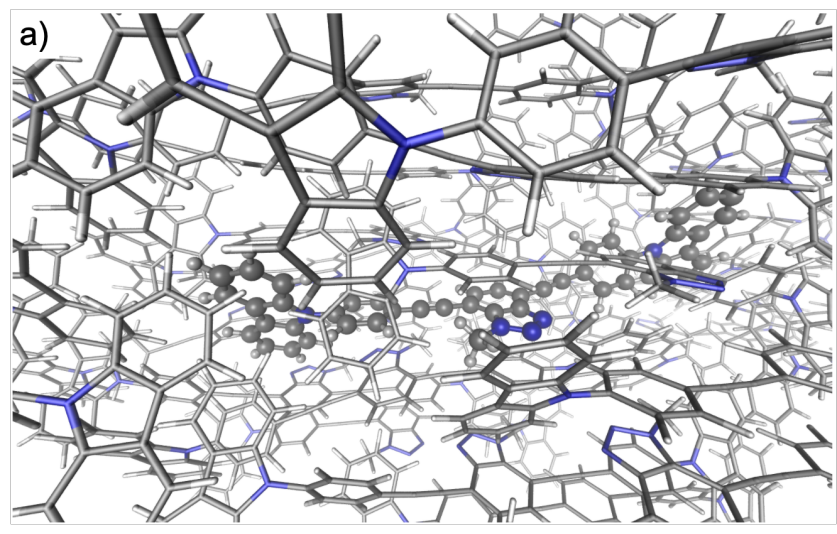

b)
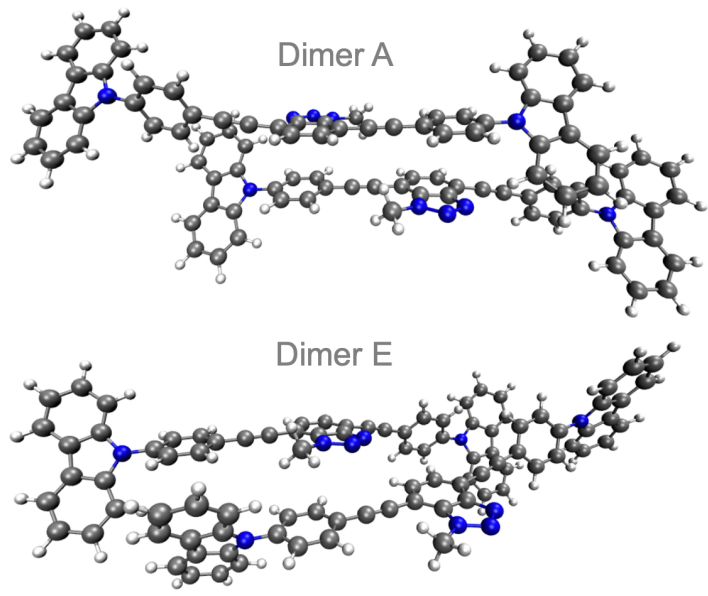

Dimer $\mathrm{F}$

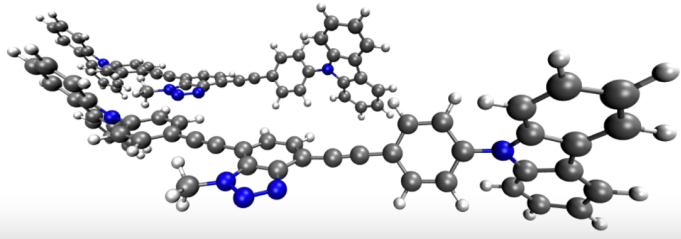

Figure 10. (a) Rotor 1 in the crystal environment and (b) dimers found in the crystalline phase.

To further understand the strong solid-state emission, we computed the absorption and emission from monomers and dimers of rotor 1 starting from its crystal environment (Figure 10). Based on the spectroscopic classification, all dimers found in the crystal could be considered as $\mathrm{H}$-dimers (Table 4). Due to the interaction with the crystal environment and 
structural reorganization in $\mathrm{S}_{1}$, the dimers show a slight red shift compared to the emission of the monomer. The shift of the dimers is in line with the exciton couplings $(12-73 \mathrm{meV})$, and they become more prominent than those found in solution (5-13 meV) due to the intermolecular interactions in the solid state. The reorganization energy is $0.52 \mathrm{eV}$ in the crystal and the barrier for the exciton hopping, estimated as $\lambda / 4$ is $0.13 \mathrm{eV}(130 \mathrm{meV})$. Given that the energy of the exciton couplings is not sufficient to overcome this barrier, no appreciable exciton migration is expected for $\mathbf{1}$ in the crystalline phase. Therefore, after relaxation in $S_{1}$, the excited states are localized on a single monomer (Supporting Information, Figure S22).

Table 4. Computed oscillator strengths $(f)$, exciton couplings $\left(J_{i j}\right)$ and $S_{1}-S_{0}$ energy gap of the monomers optimized in the crystal environment from 1.

\begin{tabular}{ccccc}
\hline Property & Monomer & Dimer A & Dimer E & Dimer F \\
\hline$f_{\mathrm{S} 1}$ & 2.69 & 0.00 & 0.03 & 0.03 \\
$f_{\mathrm{S} 2}$ & 0.16 & 4.25 & 4.06 & 4.24 \\
Aggregates & - & $\mathrm{H}$ & $\mathrm{H}$ & $\mathrm{H}$ \\
$J_{\mathrm{ij}}(\mathrm{meV})$ & - & 73.0 & 62.4 & 12.0 \\
$\Delta E_{S 1-\mathrm{SO}}$ abs $(\mathrm{nm})$ & 339 & 349 & 346 & 340 \\
$\Delta E_{S 1-\mathrm{SO}}$ em $(\mathrm{nm})$ & 395 & 401 & 398 & 396 \\
\hline
\end{tabular}

\section{Conclusions}

In summary, we successfully synthesized two novel benzotriazole-based DSE of the D- $\pi-A-$ $\pi$-D type, with excellent dual-state emission properties. They exhibit good emission in THF 
fluid solutions ( $\Phi_{\mathrm{PL}}=0.53$ and $\Phi_{\mathrm{PL}}=0.43$, for 1 and 2 , respectively). The observed positive solvatochromism is due to the rapid reorientation of the benzotriazole acceptor, facilitated by the alkyne axis in the molecules and these molecules are susceptible to changes in polarity or viscosity. In the latter case, a new emission band at $315 \mathrm{~nm}$ may originate from a portion of the twisted molecule or through a non-Kasha emission from $\mathrm{S}_{2}$, according to our TD-DFT computations.

This is the first work that describes $D-\pi-A-\pi-D$ compounds with a rotatable acceptor that show high quantum yields in both states. The exceptional quantum yields in the solid-state $\left(\Phi_{\mathrm{PL}}=0.92\right.$ and $\Phi_{\mathrm{PL}}=0.84$, for $\mathbf{1}$ and $\mathbf{2}$, respectively) results from a delicate balance between the ICT and the twisted conformation observed in the single crystal X-ray structures. The emission of both compounds is red-shifted compared to the PL in solution $\left(\Phi_{\mathrm{PL}}=0.53\right.$ and $\Phi_{\mathrm{PL}}=0.43$, for $\mathbf{1}$ and $\mathbf{2}$, respectively), with a significant bathochromic shift in the more polar and asymmetric rotor $\mathbf{1}$. The molecular symmetry of these rotors has great relevance in the crystalline packing, impacting the observed PL. We believe that the structural characteristics presented here could be extrapolated to other $D-\pi-A-\pi-D$ compounds to develop more DSE that may be applied in several optoelectronic or biomedical applications. The inclusion of new acceptors into this design and other synthetic efforts are currently underway and will be reported in due course.

\section{Conflicts of interest}

The authors declare no competing financial interest. 


\section{Acknowledgements}

We thank the financial support from PAPIIT (IN209119) and CONACYT (A1-S-32820). L.A.R.C. thanks to CONACyT for the fellowship (849196). We thank for especially technical assistance to Dr. María del Carmen García González (MS), and M. Sc. Alejandra Nuñez Pineda (CCIQS, Thermal Analysis) for technical support. The authors thank UNAM for support related to UNAM's BGSI node. RCO and FH acknowledge funding from the Leverhulme Trust (RPG-2019-122). Quantum chemistry calculations were performed using the Queen Mary's Apocrita HPC facility, supported by QMUL Research-IT and the ARCHER UK National Supercomputing Service (EP/L000202/1) via the Materials Chemistry Consortium and the Molecular Modelling Hub for computational resources, MMMHub, which is partially funded by EPSRC (EP/T022213/1).

\section{References}

[1] a) M. A. Haidekker, E. Theodorakis, Org. Biomol. Chem. 2007, 5, 1669-1678; b) M. K. Kuimova, G. Yahioglu, J. A. Levitt, k. Suhhling, J. Am. Chem. Soc. 2008, 130, 66726673; c) H. Zhu, J. Fan, J. Du, X. Peng, Acc. Chem. Res. 2016, 49, 2115-2126.

[2] a) D. Zhang, T. Yang, H. Xu, Y. Miao, R. Chen, R. Shinar, J. Shinar, h. Wang, B. Xu, J. Yu, J. Mater. Chem. C, 2021, 9, 4921-4926; b) H. Nie, K. Hu, Y. Cai, Q. Peng, Z. Zhao, R. Hu, J. Chen, S.-J. Su, A. Qin, B. Z. Tang, Mater. Chem. Front, 2017, 1, 1125-1129. 
[3] a) J. Mei, N. L. C. Leung, R. T. K. Kwok, J. W. Y. Lam, B. Z. Tang, Chem. Rev. 2015, 115, 11718-11940; b) S. Wang, X. Yang, Z. Cheng, H. Zhang, Y. Liu, Y. Wang, Angew. Chem. Int. Ed. 2015, 54, 13068-13072.

[4] a) Z. Zheng, H. Zhang, J. W. Y. Lam, B. Z. Tang, Angew. Chem. Int. Ed. 2020, 59, 98889907; b) L. Tu, Y. Xie, Z. Li, B. Z. Tang, SmartMat. 2021, 2, 326-346.

[5] a) S. Liu, Y. Li, H. Haoke, Z. Zhao, X. Lu, J. W. Y. Lam, B. Z. Tang, ACS Materials Lett. 2019, 1, 425-431; b) S. Suzuki, S. Sasaki, A. S. Sairi, Iwai, B. Z. Tang, G. Konishi, Angew. Chem. 2020, 132, 9940-9951.

[6] a) Y.-X. Li, X.- F. Yang, J.-L. Miao, Z.-W. Zhang, G.-X. Sun, CrystEngComm, 2016, 18, 2098-2104; b) C. Zheng, Q. Zang, H. Nie, W. Huang, Z. Zhao, A. Qin, R. Hu, B. Z. Tang, Mater. Chem. Front., 2018, 2, 180-188; c) S. Yang, P.-A. Yin, L. Li, Q. Peng, X. Gu, F. Gao, J. You, B. Z. Tang, Angew. Chem. Int. Ed. 2020, 59, 10136-10142; d) G. He, L. Du, Y. Gong, Y. Liu, C. Yu, C. Wei, W. Z. Yuan, ACS Omega 2019, 4, 344-351; e) J. Tong, Y. J. Wang, Z. Wang, J. Z. Sun, B. Z. Tang, J. Phys. Chem. C 2015, 119, 38, 21875-21881.

[7] a) G. Chen, W. Li, T. Zhou, Q. Peng, D. Zhai, H. Li, W. Z. Yuan, Y. Zhang, B. Z. Tang, Adv. Mater. 2015, 27, 4496-4501; b) X. Mei, J. Wang, Z. Zhou, S. Wu, L. Huang, Z. Lin, Q. Ling, J. Mater. Chem. C, 2017, 5, 2135-2141; c) Q. Qiu, P. Xu, Y. Zhu, J. Yu, M. Wei, W. Xi, H. Feng, J. Chen, Z. Qian., Chem. Eur. J. 2019, 25, 15983-15987. 
[8] a) Y. Ni, S. Zhang, X. He, J. Huang, L. Kong, J. Yang, J. Yang, Anal. Methods, 2021, 13, 2830-2835; b) Y. Zhang, Y. Qu, J. Wu, Y. Rui, Y. Gao, Y. Wu, Dyes Pigm. 2020, 179, 108431; c) H. Mori, K. Nishino, K. Wada, Y. Morisaki, K. Tanaka, Y. Chujo, Mater. Chem. Front., 2018, 2, 573-579; d) Y. Qi, Y. Wang, G. Ge, Z. Liu, Y. Yu, M. Xue, J. Mater. Chem. C, 2017,5, 11030-11038.

[9] H. Wu, Z. Chen, W. Chi, A. K. Bindra, L. Gu, C. Qian, B. Wu, B. Yue, G. Liu, G. Yang, L. Zhu, Y. Zhao, Angew. Chem. Int. Ed. 2019, 58,11419-11423.

[10] N. Venkatramaiah, G. D. Kumar, Y. Chandrasekaran, R. Ganduri, S. Patil, ACS Appl. Mater. Interfaces 2018, 10, 3838-3847.

[11] a) S. Mondal, M. Konda, B. Kauffmann, M. K. Manna, A. K. Das, Cryst. Growth Des. 2015, 15, 5548-5554; b) G. Goti, M. Cañamante, C. Coppola, A. Dessì, D. Franchi, A. Mordini, A. Sinicropi, G. Reginato, Eur. J. Org. Chem. 2021, 18, 2655-2664; c) M. Ahn, M.-J. Kim, K.-R, Wee, J. Org. Chem. 2019, 84, 12050-12057.

[12] a) R. Radhajrishnan, B. B. Sinu, V. Anilkumarf, K.G. Screejalekshmi, Dyes Pigm. 2020, 181, 108560-108567; b) R. Misra, P. Gautam, Org. Biomol. Chem., 2014, 12, 54485457; c) Y. Wu, W. Zhu, Chem. Soc. Rev. 2013, 42, 2039-2058. 
[13] J. L. Wang, Q. Xiao, J. Pei, J. Org. Lett. 2010, 12, 4164-4167; b) A. B. Ricks, G. C. Solomon, M. T. Colvin, A. M. Scott, K. Chen, M. A. Ratner, M. R. Wasielewski, J. Am. Chem. Soc. 2010, 132, 43, 15427-15434; c) Y.-L. Wang, Q.-S. Li, Z.-S. Li, Phys. Chem. Chem Phys., 2018, 20, 14200-14210.

[14] a) R. Misra, P. Gautam, Org. Biomol. Chem., 2014, 12, 5448-5457; b) R. K. Konidena, K. R. J. Thomas, S. Kumar, Y.-C. Wang, C.-J. Li, J.-H. Jou, J. Org. Chem. 2015, 80, 58125823; c ) X. Song, M. Wang, L. Kong, J. Zhao, RSC Adv., 2017, 7, 18189-18198.

[15] a) Z. Gao, W. Zhang, Y. Yan, J. Yi, H. Dong, K. Wang, J. Yso, Y. S. Zhao, ACS Nano 2018, 12, 5734-5740; b) A. Jiménez-Sánchez, E. K. Lei, S. O. Kelly, Angew. Chem. Int. Ed. 2018, 57, 8891-8895, c) A. S. Klymchenko, Acc. Chem. Res. 2017, 50, 366-375.

[16] a) K. Isayama, N. Aizawa, J. Y. Kim, T. Yasuda, Angew.Chem.Int. Ed. 2018, 57,1198211986; b) B. Zhang, h. Wu, Z. Wang, A. Qin, B. Z. Tang, J. Mater. Chem. C, 2020, 8, 4754-4762.

[17] J. Kim, A-R. Han, J. Hong, G. Kim, J. Lee, T. S. Shin, J. H. Oh, C. Yang, Chem. Mater. 2 $014,26,4933-4942$.

[18] Q. Wang, J. J. van Franeker, B. J. Bruijnaers, M. M. Wienk, R. a. Janssen, J. Mater. Chem A, 2016, 4, 10532-10541. 
[19] H. Klfout, A. Stewart, M. Elkhalifa, H. He, ACS Appl. Mater. Interfaces. 2017, 9, 46, 39873-39889.

[20] a) E. R. Sodre, B. C. Guido, P. E. D. de Souza, D. F. S. Machado, V. H. Carvalho-Silva, J. A. Caker, C. C. Gatto, J. R. Correa, T. de A. Fernandes, B. A. D. Neto, J. Org. Chem. 2020, 85, 12614-12634; b) X. Ge, y. Lou, L. Su, B. Chen, Z. Gou, S. Gao, W. Zhang, T. Chen, J. Song, h. Yang, Anal. Chem. 2020, 92, 6111-6120; c) Y. Zhang, J. Zhang, J. Shen, J. Sun, K. Wang, Z. Xie, H. Gao, B. Zou, Adv. Optical Mater. 2018, 6, 18009561800967.

[21] A. Aguilar-Granda, S. Pérez-Estrada, A. E. Roa, J. Rodríguez-Hernández, S. Hernández-Ortega, M. Rodríguez, B. Rodríguez-Molina, Cryst. Growth Des. 2016, 16, 3435-3442.

[22] a) I. Torres, J. R. Carrillo, A. Díaz-Ortíz, R. Martín, M.V. Gómez, L. Stegemann, C. A. Strassert, j. Orduna, J. Buendía, E. E. Greciano, J. S. Valera, E. Matesanz, L. Sánchez, P. Prieto, RSC Adv. 2016, 6, 36544-36553; b) D. Patel, F. Feng, Y. Ohnishi, K. A. Abboud, S. Hirata, K. S. Schanze, J. R. Reynolds, J. Am. Chem. Soc. 2012, 134, 25992612; c) I. Torres-Moya, C. Benitez-Martin, B. Donoso, C. Tardío, R. Martín, J. R. Carrillo, A. Díaz-Ortíz, F. Najera, P. Prieto, E. Perez-Inestrosa, Chem. Eur. J. 2019, 25, 
15572-15579; d) X. Ye, X. Zhao, Q. Li, y. Ma, W. Song, Y. Quan, Z. Wang, M. Wang, Z. Huang, Dyes Pigm. 2019, 164, 407-416.

[23] a) O. A. Kucherak, P. Didier, Y. Mély, A. Klymchenko, J. Phys. Chem. Lett. 2010, 1, 616-620; b) A. Klymchencko, Acc. Chem. Res. 2017, 50, 366-375.

[24] a) N. Mataga, Y. Kaifu, Y.; M. Koizumi, Bull. Chem. Soc. Jpn. 1956, 29, 465-470; b) W. Z. yuan, Y. Gong, S. Chen, X. Y. Shen, J. W. Y. Lam, P. Lu, Y. Lu, Z. Wang, R. Hu, N. Xie, H. S. Kwok, Y. Zhhang, J. Z. Sun, B. Z. Tang, Chem. Mater. 2012, 24, 1518-1528.

[25] a) M. Tanaka, S. Muraoka, Y. Matsui, E. Ohta, A. Sakai, T. Ogaki, Y. Yoshimoto, K. Mizuno, Hh. Ikeda, ChemPhotoChem 2017, 1, 188-197; b) R. K. Konidena, K. R. J. Thomas, D. K. Dubey, S. Sahoo, J.-H. Jou, ChemPhotoChem 2020, 4, 5364-5375.

[26] T. Jadhav, B. Dhokale, Y. Patil, S. M. Mobin, R. Misra, J. Phys. Chem. C 2016, 120, 24030-24040.

[27] a) M. Ahn, M.-J. Kim, D. W. Cho, K.-R, Wee, J. Org. Chem. 2019, 86, 403-413; b) I. Torres-Moya, C. Benitez-Martin, B. Donoso, C. Tardío, R. Martín, J. R. Carrillo, A. DíazOrtíz, F. Najera, P. Prieto, E. Perez-Inestrosa, Chem. Eur. J. 2019, 25, 15572-15579; c) Z.-E. Chen, Q.-I. Qi, H. Zhang, Spectrochim. Acta - A: Mol. Biomol. Spectrosc. 2020, 
238, 118384-118392; d) W. fang, K. Liu, G. Wang, Y. Liang, R. Huang, T. Liu, L. Ding, J. Peng, H. Peng, Y. Fang, Anal. Chem. 2021, 93, 8501-8507.

[28] a) G. S. Kottas, L. I. Clarke, D. Horinek, J. Michl, Chem. Rev. 2005, 105, 1281-1376; b) M. Levitus, K. Schmieder, H. Ricks, K. D. Shimizu, U. H. F. Bunz, M. A. Garcia-Garibay, J. Am. Chem. Soc. 2001, 123, 4259-4265; c) M. Hughs, M. Jimenez, S. Khan, M. A. Garcia-Garibay, J. Org. Chem. 2013, 78, 11, 5293-530.

[29] a) S. D. Choudhury, S. Muralidharan, H. Pal, Phys. Chem. Chem. Phys., 2014, 16, 11509-11518; b) Z. Peng, Z. Wang, Z. Huang, S. Liu, P. Lu, Y. Wang, J. Mater. Chem. C, 2018, 6, 7864-7873; c) J. C. del Valle, J. Catalán, Phys. Chem. Chem. Phys., 2019, 21, 10061-10069; d) A. P. Demchencko, V. I. Tomin, P.-T. Chou, Chem. Rev. 2017, $117,13353-13381$.

[30] a) Q. Shao, K. Liang, H. Ling, Y. Wang, Z. Yang, G. Xia, H. Wang, J. Mater. Chem. C, 2020, 8, 4549-4556; b) M. Huang, J. Zhou, K. Xu, X. Zhu, Y. Wan, Dyes Pigm. 2019, 160, 839-847. ; c) H. Liu, S. Zhang, L. Ding, Y. Fang, Chem. Commun. 2019, 55, 1146211465; d) Y. Xu, L. Ren, D. Dang, Y. Zhi, X. Wang, L. Meng, Chem. Eur. J. 2018, 24, 10383-10389; e) J. Zhou, M. Huang, X. Zhu, Y. Wan, Chin. Chem. Lett. 2021, 32, 445448; f) X. Zheng, W. Zhu, C. Zhang, Y. Zhang, C. Zhong, H. Li, X. Wang, C. Yang, J. Am. Chem. Soc. 2019, 141, 4704-4710. 
[31] V. S. Padalkar, D. Sakamaki, K. J. Kuwada, A. Hotio, HH. Okamoto, N. Tohnai, T. Akutagawa, K. Sakai, S. Seki, Asian J. Org. Chem. 2016, 5,938-945.

\section{Table of Contents Graphic}

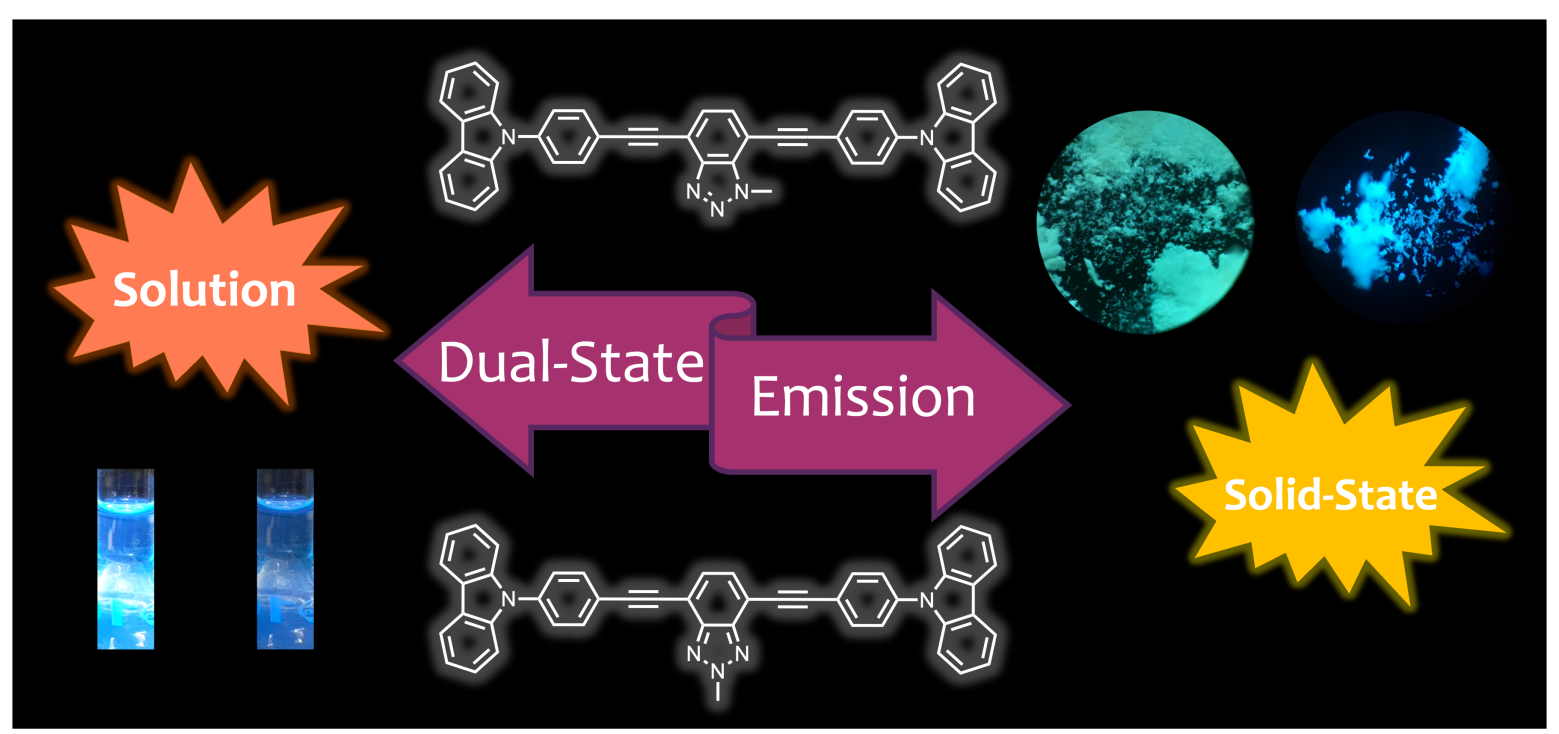


